[Chem. Pharm. Bull.

[35(11)4557-4561(1987)

\title{
Stereoselectivity in the Mechanism of Acid Hydrolysis of Mitomycins
}

\author{
Willy J. M. UNDERBERG ${ }^{*, a}$ and Jos H. BEIJNEN ${ }^{b}$ \\ Department of Chemical Pharmacy, Subfaculty of Pharmacy, State University of Utrecht, ${ }^{a}$ \\ Catharijnesingel 60,3511 GH Utrecht, The Netherlands and Slotervaart \\ Hospital/Netherlands Cancer Institute, ${ }^{b}$ Louwesweg 6, \\ 1066 EC Amsterdam, The Netherlands
}

(Received March 23, 1987)

\begin{abstract}
The stereoselectivity in the acid hydrolysis mechanism of mitomycins was studied. The predominance of the 1,2-cis-mitosene degradation products occurring at low $\mathrm{pH}$ was ascribed to the directing force exterted on the incoming nucleophile by the protonated 2 -amino function of an intermediate in the process as well as to steric hindrance due to the orientation of the $\mathrm{C}_{9}$ urethane substituent in one of the degradation steps preceding the formation of the intermediate. The differences in electron density in the intermediate chromophore and the resulting differences in $\mathrm{p} K_{\mathrm{a}}$ value of the amino function involved are discussed.
\end{abstract}

Keywords_-mitomycin; acid degradation; stereoselectivity; $\mathrm{pH}$ dependence

Mitomycins are a group of potent antitumor antibiotics, acting by covalent binding and cross-linking of deoxyribonucleic acid (DNA). ${ }^{1,2)}$ The compounds have the general structure given in Fig. 1 (I).$^{3,4)}$ Activation of mitomycins in vivo may occur either after reduction ${ }^{5,6)}$ or under acidic conditions. ${ }^{7-9)}$ Under such conditions the compounds are converted into 2amino-1-hydroxymitosenes (II, Fig. 1). During this conversion active intermediates exist that are responsible for the alkylating process. Both activation pathways show much similarity, only differing in the oxidation level of the reactive intermediate species. The in vitro degradation of the mitomycins has been studied extensively ${ }^{10-26)}$ and several mechanisms for this process have been suggesed. ${ }^{11-14,16,26)}$ One of the interesting aspects of the process is the predominance of the 1,2-cis-2-amino-1-hydroxymitosene degradation products ${ }^{22-25)}$ in contrast to the occurrence of 1,2-trans-orientated amino alcohols during acid catalyzed ring opening of simple aziridines ${ }^{27}$ as well as the $\mathrm{pH}$ dependence of the ratio between the cis and trans isomers. ${ }^{16)}$ The present study is focused on this aspect of the acid degradation of mitomycins.
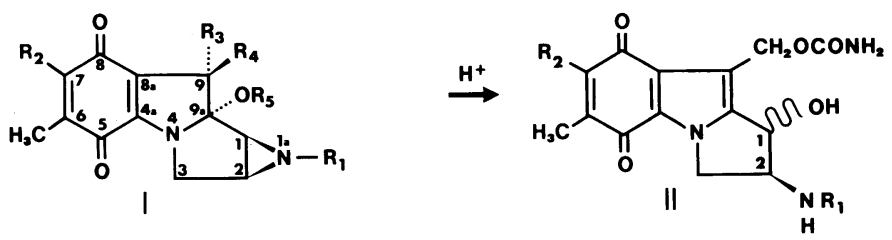

$\begin{array}{llllll} & \mathrm{R}_{1} & \mathrm{R}_{2} & \mathrm{R}_{3} & \mathrm{R}_{4} & \mathrm{R}_{5} \\ \text { mitomycin A } & \mathrm{H} & \mathrm{H}_{3} \mathrm{CO} & \mathrm{H} & \mathrm{CH}_{2} \mathrm{OCONH}_{2} & \mathrm{CH}_{3} \\ \text { mitomycin B } & \mathrm{CH}_{3} & \mathrm{H}_{3} \mathrm{CO} & \mathrm{CH}_{2} \mathrm{OCONH}_{2} & \mathrm{H} & \mathrm{H} \\ \text { mitomycin C } & \mathrm{H} & \mathrm{H}_{2} \mathrm{~N} & \mathrm{H} & \mathrm{CH}_{2} \mathrm{OCONH}_{2} & \mathrm{CH}_{3} \\ \text { porfiromycin } & \mathrm{CH}_{3} & \mathrm{H}_{2} \mathrm{~N} & \mathrm{H} & \mathrm{CH}_{2} \mathrm{OCONH}_{2} & \mathrm{CH}_{3}\end{array}$

Fig. 1. Structures of Mitomycins and Mitosene Degradation Products 


\section{Experimental}

Mitomycin A and mitomycin B were gifts from Dr. K. Shirahata, Kyowa Hakko Kogyo Chemical Co., Tokyo, Japan; mitomycin $C$ was supplied by Bristol Myers, Amstelveen, The Netherlands and porfiromycin was obtained from Cyanamid, Pearl River, New York, U.S.A. Degradation studies were carried out at $25 \mathrm{C}$ in $0.001 \mathrm{M}$ acetate/phosphate buffers of various $\mathrm{pH}$ in the acid region, and the resulting mixtures were analyzed using high performance liquid chromatography (HPLC) procedures described earlier. ${ }^{19.20)}$ These stability indicating procedures enable the assay of the parent compounds as well as each individual degradation product. Half-wave potentials were determined at $25 \mathrm{C}$ and $\mathrm{pH} 7.4$ according to previously described procedures. ${ }^{101}$

\section{Results}

The degradation of mitomycins in acid solution under the experimental conditions yields only two products, cis- and trans-2-amino-1-hydroxymitosene. The ratio between the concentrations of those two products is $\mathrm{pH}$-dependent but, at a given $\mathrm{pH}$, independent of the degradation stage. Figure 2 represents the $\mathrm{pH}$ dependences of the cis/trans ratios for mitomycins $\mathrm{A}, \mathrm{B}$ and $\mathrm{C}$ and porfiromycin. The latter two show identical behavior with an inflexion in the curve at $\mathrm{pH} 2.8$, whereas mitomycins A and $\mathrm{B}$ show this inflexion at $\mathrm{pH} 1.5$. Figure 2 also demonstrates that at $\mathrm{pH} 1$ the ratio for mitomycin $\mathrm{B}$ is 6.0 , that for mitomycin $\mathrm{A}$ is 3.5, and those for mitomycin $\mathrm{C}$ and porfiromycin are 4.5 . At $\mathrm{pH} 6$ all compounds show ratios between 1.5 and 1.1. As reported earlier ${ }^{16)}$ the inflexion in the curve of mitomycin $\mathrm{C}$ (Fig. 2) agrees with the $\mathrm{p} K_{\mathrm{a}}$ of an intermediate in the acid hydrolysis of the compound. Consequently, the $\mathrm{p} K_{\mathrm{a}}$ values of the mitomycins $\mathrm{A}$ and $\mathrm{B}$ intermediates should be 1.5 . The replacement of the 7-amino function by a methoxy group must account for this shift, since this replacement results in a different electron density in the chromophoric system. To establish these electron densities, half-wave potentials for the reduction of all mitosanes and mitosenes under investigation were determined (Table I). The results clearly indicate the decrease in electron density in mitomycins $\mathrm{A}$ and $\mathrm{B}$ and their mitosene degradation products in comparison to mitomycin $\mathrm{C}$ and porfiromycin and the corresponding mitosenes. Within the

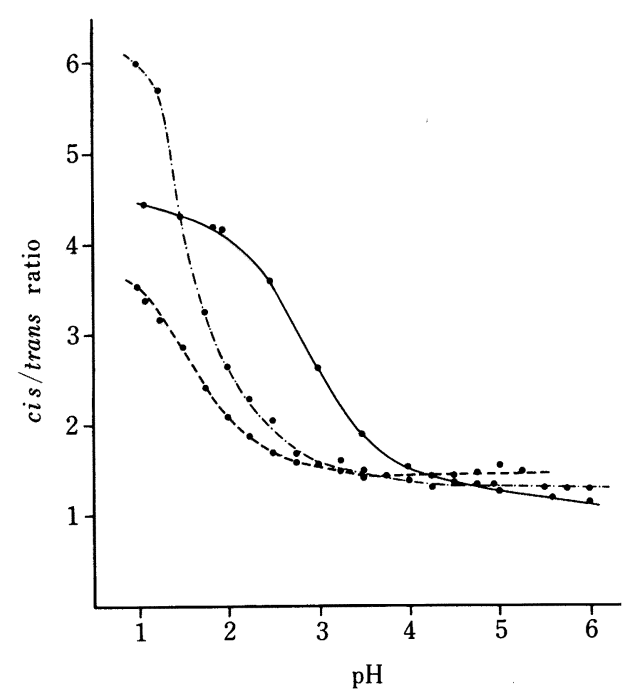

Fig. 2. pH Dependence of the Ratio between the Mole Fractions of 1,2-cis and 1,2-trans Mitosenes Originating from Mitomycin A (--- ), Mitomycin B (-----), and Mitomycin $\mathrm{C}$ and Porfiromycin (-)
TABLE I. Half-Wave Potentials for the Reduction of Mitomycins and Their Degradation Products in 0.1 $\mathrm{M}$ Phosphate Buffer pH $7.4\left(25^{\circ} \mathrm{C}\right)$

\begin{tabular}{lc}
\hline \hline \multicolumn{1}{c}{ Compound } & $E_{1 / 2}(\mathrm{mV})$ \\
\hline Mitomycin A & -182 \\
Mitomycin B & -155 \\
Mitomycin C & -365 \\
Porfiromycin & -367 \\
Mitomycin A mitosenes & -315 \\
Mitomycin B mitosenes & -310 \\
Mitomycin C mitosenes & -475 \\
Porfiromycin mitosenes & -465 \\
\hline
\end{tabular}


two groups, however, the values are the same. This indicates the same $\mathrm{p} K_{\mathrm{a}}$ value for the intermediates originating from mitomycin $\mathrm{A}$ and $\mathrm{B}$ but with a lower value than the also identical values for the intermediates originating from mitomycin $\mathrm{C}$ and porfiromycin.

\section{Discussion}

The $\mathrm{pH}$ dependence of the cis/trans ratio of the mitosenes, resulting from mitomycin $\mathrm{C}$ degradation, was ascribed to the 2-amino function of an intermediate in the acid catalyzed degradation of the compound, ${ }^{16)}$ rather than to the $\mathrm{p} K_{\mathrm{a}}$ of the parent compound. Further evidence for the validity of this hypothesis is provided by the lower value of the inflexion in the $\mathrm{pH}$ dependences of these ratios for mitomycins $\mathrm{A}$ and $\mathrm{B}$, having similar $\mathrm{p} K_{\mathrm{a}}$ values $^{20)}$ but expected to possess lower electron densities in the chromophores. The degradation mechanism for mitomycin A and B is now presented in Fig. 3. Since porfiromycin and mitomycin $\mathrm{C}$ show identical curves, the $\mathrm{p} K_{\mathrm{a}}$ of the intermediate resulting from these compounds must be the same. The half-wave potentials for both compounds are also identical, which is in agreement with the similar $\mathrm{p} K_{\mathrm{a}}$ values for the intermediates resulting from both compounds.

The conclusion must be that the $\mathrm{N}$-1a methyl substituent has no significant influence on
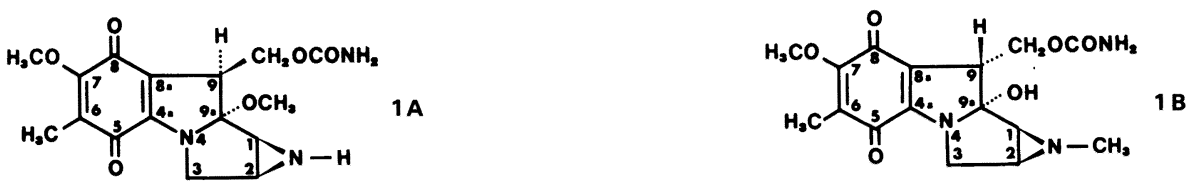

$\downarrow^{+}$

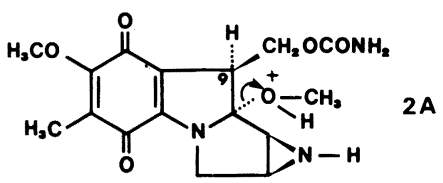

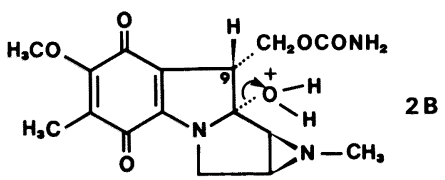

$\downarrow-\mathrm{HOCH}_{3}$

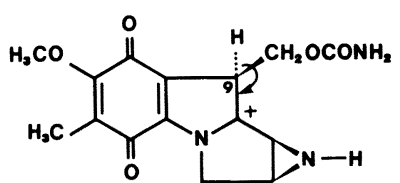

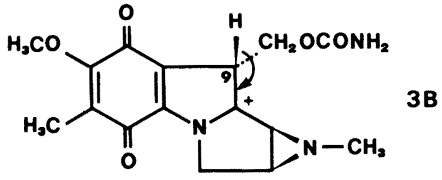

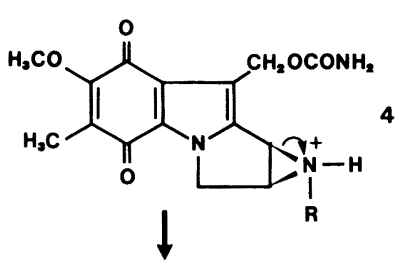<smiles>COc1c(C)c(=O)c2c(CO)[c+]c3n(c=2c1=O)CC=3NP</smiles><smiles>COC1=C(C)C(=O)C2=C(C1=O)N1CC(NP)=C1C(=O)O2</smiles>

Fig. 3. Degradation Scheme of Mitomycin A (1A) and Mitomycin B (1B) 
the stereospecificity of the hydrolysis, i.e., the direction of the incoming nucleophile. The halfwave potentials of mitomycins A and B and their mitosene degradation products are much higher, due to the stronger electron-withdrawing properties of the 7-methoxy group in contrast to the electron-donating nature of the 7-amino substituent. A lower electron density in the chromophore results in an increased reduction capability of the quinoid moiety. Furthermore, a lower electron density decreases the stability of the protonated form of the intermediate (5, Fig. 3), due to the resulting decrease in inductive compensation of the positive charge at $\mathrm{C}_{1}$. The half-wave potentials of the mitosene degradation products provide the best approach of the electron density in the intermediate 5 chromophore. Moreover, the replacement of the 7-amino function by a methoxy group diminishes the possibilities of mesomeric and tautomeric stabilization of the protonated intermediate 5 . These two changes, due to the presence of the 7-methoxy function, explain the decrease in $\mathrm{p} K_{\mathrm{a}}$ of $\mathbf{5}$ originating from mitomycins $\mathrm{A}$ and $\mathrm{B}$, as well as the similarity of the $\mathrm{p} K_{\mathrm{a}}$ values, because the influences of the other substituents can be considered negligible.

Figure 2 shows that the cis/trans ratios for mitomycin $\mathrm{C}$ and porfiromycin degradation processes are identical at every $\mathrm{pH}$. The identical $\mathrm{p} K_{\mathrm{a}}$ of the intermediates and the identical stereochemistry of the parent compounds are the explanation for this phenomenon. However, in spite of the identical $\mathrm{p} K_{\mathrm{a}}$ of the intermediates arising from mitomycins $\mathrm{A}$ and $\mathrm{B}$, the cis/trans mitosene ratios for both compounds are significantly different, especially at low $\mathrm{pH}$. Thus; another influence, apart from the protonated 2-amino group in $\mathbf{5}$, must exist in directing the incoming nucleophile. This influence must be ascribed to the differences in structure of the two compounds. The presence of a hydroxy group at $\mathrm{C}_{9 \mathrm{a}}$ in mitomycin $\mathrm{B}$ instead of the methoxy group in mitomycin $\mathrm{A}$ is unlikely to account for the difference between these ratios since the stereochemical orientation of the groups is identical and the cleavage of both groups is generally a very fast kinetic process. It is remarkable that the cis orientation of the $\mathrm{C}_{9}$ urethane substituent with the 1,2-fused aziridine ring in mitomycin A parallels a lower ratio whereas the trans orientation in mitomycin B is accompanied by a higher cis/trans ratio of the diastereomeric degradation products. If the final orientation of the $C_{1}$ substituent were to occur solely in $\mathbf{5}$, the only directing force would be the protonated 2-amino function, since in $\mathbf{5}$ the $\mathrm{C}_{9}$ substituent has a coplanar orientation. Consequently, in this case, mitomycin $\mathrm{A}$ and mitomycin B should yield the mitosene degradation products in identical ratios. The additional stereospecificity must therefore have its origin in an earlier stage. The cis/trans ratio after degradation of 1,2-aziridinomitosene (4, Fig. 3) was found by Cheng and Remers ${ }^{22}$ to be 3.2 at $\mathrm{pH} 1.30$, while mitomycin $\mathrm{B}$ at this $\mathrm{pH}$ yields a ratio of 5.7.2) This is in accordance with our observations with mitomycin B (Fig. 2). These data suggest that steric hindrance may determine in part the orientation of the $\mathrm{C}_{1}$ substituent. The fact that no 9-epimitomycin $\mathrm{B}$ (9ademethylmitomycin A) or 9-epi-9a-epimitomycin B and 9a-epimitomycin B are formed as degradation products of mitomycin $\mathrm{A}$ and mitomycin $\mathrm{B}$, respectively, indicates that in this case also, the degradation steps preceding the formation of intermediate 4 (Fig. 3) are very fast. Consequently, the direction of the incoming nucleophile may in part be determined in one of these steps, resulting in the enhanced predominance of the cis stereospecificity at $C_{1}$ in mitomycin B.

Thus, in addition to the principle driving force (the protonated 2-amino function in intermediate 4) trans orientation of the $\mathrm{C}_{9}$ urethane substituent with the 1,2-fused aziridine ring results in an increase in the cis/trans mitosene ratio on degradation of mitomycin $\mathrm{B}$.

\section{References}

1) S. K. Carter and S. T. Crooke, "Mitomycin C: Current Status and New Developments," Academic Press, New York, 1979, p. 1.

2) W. A. Remers, "The Chemistry of Antitumor Antibiotics," John Wiley \& Sons, New York, 1979, p. 221. 
3) K. Shirahata and N. Hirayama, J. Am. Chem. Soc., 105, 7199 (1983).

4) U. Hornemann and M. J. Heins, J. Org. Chem., 50, 1301 (1985).

5) W. Szybalski and V. N. Iyer, “Antibiotics I, Mechanism of Action,” Springer-Verlag, New York, 1967, p. 221.

6) H. W. Moore, Science, 197, 527 (1977).

7) J. W. Lown, A. Begleiter, D. Johnson, and A. R. Morgan, Can. J. Biochem., 54, 110 (1976).

8) J. W. Lown and G. Wier, Can. J. Biochem., 56, 296 (1978).

9) K. A. Kennedy, J. D. McGurl, L. Leondaridis, and O. Alabaster, Cancer Res., 45, 3541 (1985).

10) E. R. Garrett, J. Med. Chem., 6, 488 (1963).

11) C. L. Stevens, K. G. Taylor, M. E. Munk, W. S. Marshall, K. Noll, G. D. Shah, L. G. Shah, and K. Uzu, J. Med. Chem., 8, 1 (1965).

12) B. S. Iyengar and W. A. Remers, J. Med. Chem., 28, 963 (1985).

13) R. A. McClelland and K. Lam, J. Am. Chem. Soc., 107, 5182 (1985).

14) W. J. M. Underberg and H. Lingeman, J. Pharm. Sci., 72, 549 (1983).

15) W. J. M. Underberg and H. Lingeman, J. Pharm. Sci., 72, 553 (1983).

16) J. H. Beijnen and W. J. M. Underberg, Int. J. Pharm., 24, 219 (1985).

17) J. H. Beijnen, J. Den Hartigh, and W. J. M. Underberg, J. Pharm. Biomed. Anal., 3, 59 (1985).

18) J. H. Beijnen, J. Den Hartigh, and W. J. M. Underberg, J. Pharm. Biomed. Anal., 3, 71 (1985).

19) J. H. Beijnen, H. Rosing, and W. J. M. Underberg, Arch. Pharm. Chem. Sci. Ed., 13, 58 (1985).

20) J. H. Beijnen, O. A. G. J. van der Houwen, H. Rosing, and W. J. M. Underberg, Chem. Pharm. Bull., 34, 2900 (1986).

21) U. Hornemann, P. J. Keller, and K. Takeda, J. Med. Chem., 28, 31 (1985).

22) L. Cheng and W. A. Remers, J. Med. Chem., 20, 767 (1977).

23) W. G. Taylor and W. A. Remers, J. Med. Chem., 18, 307 (1975).

24) W. G. Taylor and W. A. Remers, Tetrahedron Lett., 39, 3483 (1974).

25) M. Tomasz and R. Lipman, J. Am. Chem. Soc., 101, 6063 (1979).

26) I.-C. Chiu and H. Kohn, J. Org. Chem., 48, 2857 (1983).

27) O. C. Dermer and G. E. Ham, "Ethyleneimine and Other Aziridines," Academic Press, New York, 1969, p. 206. 